\title{
СОЦИОЛОГИЯ ТРУДА
}

\section{УДК 316.334}

ПРЯЖНИКОВА О.Н. ${ }^{*}$ РОСТ ОБЪЕМОВ УДАЛЕННОЙ РАБОТЫ В ПЕРИОД ПАНДЕМИИ COVID-19: ПОСЛЕДСТВИЯ И ПЕРСПЕКТИВЫ. DOI: 10.31249/rsoc/2021.03.10

Аннотация. Рассматриваются эффекты влияния роста объемов удаленной работы, обусловленного мерами борьбы с распространением нового коронавируса, на производительность, благополучие и жизненные приоритеты работников, а также их ожидания, связанные с комбинированным режимом работы из дома и в офисе и соответствующей трансформацией офисного рабочего пространства.

Ключевые слова: удаленная работа; работа в офисе; рабочее место; производительность; культура организации; благополучие работников; офисное пространство; COVID-19.

PRYAZHNIKOVA O.N. The proliferation of remote work during the COVID-19 pandemic: consequences and prospects.

Abstract. The review examines the effects of increased remote work, due to the measures aimed at preventing the spread of the new coronavirus, on employees' productivity, wellbeing and life priorities, as well as their expectations towards hybrid work patterns that combine work from home and at the office, and corresponding transformation of the office workspace.

Keywords: remote work; office work; workplace; performance; organization culture; employee wellbeing; office space; COVID-19.

* Пряжникова Ольга Николаевна - научный сотрудник отдела экономики Института научной информации по общественным наукам РАН.

E-mail: olga.priazhnikova@inion.ru 


\section{Рост объемов удаленной работы в период пандемии COVID-19: последствия и перспективы}

Для цитирования: Пряжникова О.Н. Рост объемов удаленной работы в период пандемии COVID-19: последствия и перспективы // Социальные и гуманитарные науки. Отечественная и зарубежная литература. Cер. 11: Социология. - 2021. - № 3. - С. 116-125.

DOI: $10.31249 / \mathrm{rsoc} / 2021.03 .10$

С введением мер изоляции и социального дистанцирования в рамках борьбы с распространением COVID-19, как показывает ряд недавно проведенных исследований [Dingel, Neiman, 2020; Mueller-Langer, Gomez-Herrera, 2020; Ляшок, 2021], на рынках труда произошел рост доли работников, пользующихся режимом удаленной работы ${ }^{1}$.

Работодатели все чаще используют удаленную работу, так как становятся очевидны преимущества, которые дает этот режим труда для сохранения экономической активности на прежнем уровне в условиях пандемии, а кроме того, для сокращения издержек на аренду и содержание офисных площадей. Удаленный режим приносит выгоду и сотрудникам. Работая из дома, они перестают тратить время на поездки в офис и обратно, что увеличивает объем свободного времени и сокращает транспортные расходы. Имеются и негативные эффекты удаленной работы: работа из дома сокращает возможности совместной работы с коллегами и снижает вовлеченность сотрудников в рабочие процессы, что, в свою очередь, тормозит развитие инноваций и рост производительности труда [The costs ..., 2020, p. 4].

Анализ плюсов и минусов удаленной работы, проведенный специалистами компании PricewaterhouseCoopers [The costs ..., 2020] позволил выделить ряд последствий увеличения объемов работы из дома и ее комбинирования с работой в офисе. Так, работодатели, скорее всего, будут стремиться к равномерному распре-

${ }^{1}$ Удаленная работа - это форма организации и / или выполнения работы с использованием информационных технологий при наличии трудового договора или какой-либо формы трудовых отношений, когда работа, которая может быть выполнена в помещении работодателя, осуществляется вдали от этих помещений на регулярной основе. См.: Framework agreement on telework / Gabaglio E., General secretary of the European trade union confederation, on behalf of the trade union delegation. - Brussels, 2002. - Jul 16. - URL: https://resourcecentre.etuc.org/sites/ default/files/2020-09/Telework\%202002_Framework\%20Agreement\%20-\%20EN.pdf (accessed: 05.04.2021). 
делению дней работы сотрудников из дома и в офисе, так как это позволяет уменьшить потребность в офисных площадях и сократить сопутствующие расходы на электричество, отопление, уборку и организацию питания сотрудников.

Кроме того, может возникнуть ряд последствий, которые в меньшей степени поддаются количественной оценке. Они связаны прежде всего с поддержанием корпоративной культуры. Сокращение непосредственных контактов с коллегами создает угрозу эрозии корпоративной культуры. Это, в свою очередь, может привести к уменьшению эффективности сотрудничества между коллегами и в последующем к торможению инноваций, ослаблению бренда, снижению лояльности клиентов, а в долгосрочной перспективе негативно сказаться на прибыльности компании. Вместе с тем работники, работая удаленно и сочетая работу из дома и в офисе, оценивают свою производительность выше, чем в случае, когда они работают только в офисе [The costs ..., 2020]. Таким образом, при применении режима удаленной работы вероятен рост индивидуальной производительности работников, но при этом снижение производительности трудовых процессов, требующих тесного сотрудничества коллег.

Эксперты консалтинговой фирмы Global Workplace Analytics указывают на тот факт, что расширение режима удаленной работы сокращает количество дней невыхода на работу (или прогулов) изза ухудшения состояния здоровья или личных обстоятельств. Это объясняется тем, что сокращаются контакты и снижается заболеваемость инфекционными болезнями, уменьшается вероятность травматизации на рабочем месте или в транспорте при поездке на работу. Благодаря удаленному режиму может сокращаться срок выхода на работу после рождения ребенка, восстановления от хирургических вмешательств или серьезных заболеваний, так как не требуются перемещения вне дома. Бо́льшая гибкость в организации трудового процесса при работе из дома позволяет совмещать личные неотложные дела и работу, что позволяет работнику обойтись без оформления отгула. Снижается стрессовая нагрузка, связанная с поездками и работой в офисе, где чаще, чем дома, возникают дискомфортные ситуации [The business case ..., 2021, p. 13].

Влияние удаленной работы на текучесть кадров оценивается неоднозначно. С одной стороны, ослабление корпоративной куль- 


\section{Рост объемов удаленной работы в период пандемии COVID-19: последствия и перспективы}

туры, о чем говорилось выше, может способствовать тому, что сотрудники, которые в условиях работы из дома в меньшей степени ощущают свою связь с компанией, будут более склонны к уходу из нее. С другой стороны, бо́льшая гибкость при организации работы из дома сопровождается сокращением текучки кадров [The costs ..., 2020 , p. 6]. Удаленная работа позволяет удерживать талантливых работников, ценящих гибкий подход к рабочим процессам, и расширяет возможности их поиска и найма, так как снимает географические ограничения. Кроме того, многие работники, перед которыми встает необходимость осуществлять уход за членами семьи, получают шанс сохранить занятость, совместив ее с выполнением семейных обязанностей [The business case ..., 2021, p. 13].

Работая из дома, сотрудники отмечают улучшение баланса между работой и личной жизнью. Они указывают на улучшение сна, возможность организовать более здоровое питание и уделять больше времени физическим упражнениям. Все это в сочетании со снижением инфекционных заболеваний вследствие сокращения очных контактов с коллегами и бизнес-партнерами приносит пользу здоровью работников [The business case ..., 2021, p. 27].

В целом массовый переход на режим работы из дома показал, что при наличии адекватной технологической поддержки сотрудники смогли адаптироваться к мерам изоляции и сохранить эффективность своей работы без существенной потери производительности [Reimagining ..., 2020, p. 2]. Вместе с тем в новых условиях у работников формируются новые ожидания, связанные с дальнейшими изменениями организации рабочих процессов и рабочего места.

Опрос 2033 офисных служащих разных отраслей из десяти стран мира, проведенный в октябре 2020 г. ведущей компанией в сфере профессиональных услуг JLL (Jones Lang Lasalle), был посвящен выявлению предпочтений рабочей силы, касающихся возможностей комбинирования удаленной работы и работы в офисе. $24 \%$ опрошенных выразили желание вернуться или продолжить работу в офисе, $50 \%$ хотят работать как в офисе, так и удаленно, а $26 \%$ не хотят больше возвращаться на офисное рабочее место. Ответы на вопрос «Сколько дней в неделю вы хотели бы работать удаленно после COVID-19?» показали, что работники хотели бы, чтобы время удаленной работы удвоилось с 1,2 дня (предпочтения 
до пандемии) до 2,4 дня в неделю после пандемии. $72 \%$ сотрудников хотят продолжить работать из дома в среднем 2 дня в неделю. Выросла доля работников (с 30\% в докризисный период до 40\% в настоящий момент), предпочитающих работать удаленно на альтернативных рабочих местах вне офиса, например в коворкингах [Reimagining ..., 2020, p. 5].

Интересно, что, работая из дома, сотрудники ожидают получить поддержку работодателей при оснащении нового рабочего места соответствующими технологическими инструментами, получить денежные выплаты для оснащения комфортного и эргономичного рабочего пространства или даже для расширения собственного жилища и покупки дополнительной жилой площади под рабочее место. Кроме того, работники хотели бы, чтобы за счет компании покрывались их расходы на оплату электричества и услуг интернет-провайдера, доступа к таким онлайн-сервисам, как платформы для занятий спортом, доставки еды, удаленных медицинских консультаций и т.д.

Важно отметить, что эксперты указывают на тот факт, что эффективность ряда рабочих процессов и реализации мер по профессиональному развитию работников выше при работе в офисе. Большинство респондентов (70\%) считают, что офисная среда более благоприятна для тимбилдинга, получения работниками поддержки от менеджеров. Менеджеры подчеркивают, что при работе в офисе им легче осуществлять функции руководства, а именно реализовывать свои лидерские и управленческие компетенции, а также оперативно решать комплексные операционные проблемы. Кроме того, более плодотворные условия для профессионального и личного общения коллег, а также для обучения и профессионального развития, по мнению участников опроса, легче обеспечить внутри корпоративного офиса [Reimagining ..., 2020, p. 9].

Анализ особенностей удаленной работы выявил наличие трудностей в поддержании эффективной совместной работы нескольких или широкого круга коллег в режиме онлайнсотрудничества. При этом опрошенные заявляют, что при работе дома им легче переключаться с решения сложных заданий на другую деятельность, а также концентрироваться при выполнении рабочих функций [Reimagining ..., 2020, p. 16]. Традиционная организация пространства современного офиса, таким образом, при- 


\section{Рост объемов удаленной работы в период пандемии COVID-19: последствия и перспективы}

знается большинством опрошенных неудовлетворительной для комфортного переключения с одной рабочей задачи на другую и для достижения необходимого уровня концентрации на рабочем процессе.

При вынужденной изоляции одно из главных ожиданий работников от возвращения к работе в офисе - это обретение пространства, создающего ощущение сообщества. Почти половина респондентов говорят о потребности в том, чтобы организация офисного пространства расширила возможности социализации и взаимодействия с коллегами, а также прямого контакта с природной средой, например с зелеными насаждениями. Работники хотели бы пользоваться такими пространствами для: неформального общения внутри коллектива (кофейные / чайные зоны, террасы); концентрации на выполняемых задачах (кабины для ведения телефонных переговоров, фокус-комнаты (focus rooms)); общения с природой (открытые площадки с растениями); обучения и профессионального развития (учебные классы, библиотеки, виртуальные кафе); реализации творческого подхода к решению рабочих задач (комнаты «дизайн-мышления» ${ }^{1}$, производственные лаборатории (fab labs), лаборатории инноваций); для разработки проектов и совместной работы (питч-комнаты (pitch rooms) или проектные комнаты); для художественного самовыражения; для работы над личными проектами с использованием инфраструктуры компании [Reimagining ..., 2020, p. 18].

В связи с происходящими изменениями в организации трудовых процессов, в том числе связанными с пандемией COVID-19, работники все чаще начинают переосмысливать свои жизненные приоритеты, придавая больше ценности таким аспектам, как качество жизни, взаимодействие с другими людьми и личные интересы. Исследование показало, что на первое месте по значимости приоритетов баланс между работой и личной жизнью ставят 72\% работников, а достойную заработную плату - лишь 69\%. Сознательно выстроенный здоровый образ жизни, связанный с местным сообществом (conscious, local and healthy lifestyle) становится та-

${ }^{1}$ Дизайн-мышление (design thinking) - методология решения различных задач, основывающаяся на творческом, а не аналитическом подходе. Главной особенностью дизайн-мышления является не критический анализ, а творческий процесс. 
кой же важной ценностью, как и реализация в профессии, и приводится в качестве приоритета более $60 \%$ работников [Reimagining ..., 2020, p. 11].

В результате меняющейся системы приоритетов при формировании образа жизни работники все чаще стремятся иметь более гибкие условия занятости, чтобы расширить возможности достижения баланса между трудовой и личной жизнью. Помимо возможности работать из дома $71 \%$ работников ожидают от работодателя повышения гибкости графика работы и предоставления возможности использовать различные альтернативные варианты места работы, как внутри офиса компании (57\%), так и в общедоступных пространствах - коворкингах (43\%). Кроме того, 74\% опрошенных хотели бы перейти на четырехдневную рабочую неделю [Reimagining ..., 2020, p. 12].

$75 \%$ сотрудников также ожидают, что работодатели будут уделять больше внимания заботе об их здоровье и благополучии и предоставлять им новые виды услуг. Речь идет, например, об обеспечении сотрудников в течение рабочего дня питанием высокого качества, оплате услуг онлайн-сервисов, спортивных центров, салонов красоты и услуг по присмотру за детьми [Reimagining ..., 2020, p. 14].

При возобновлении работы из офиса работники ожидают увеличения объемов цифрового взаимодействия и исключения в краткосрочной перспективе из рабочих процессов очных встреч с большим числом участников. Треть опрошенных сотрудников рассчитывают, что по возвращении в офис им будет обеспечена работа с меньшей плотностью контактов с коллегами и, соответственно, разделение рабочего пространства на изолированные зоны. Таким образом, процессы трансформации рабочих процессов, ускорившиеся во многом в результате пандемии COVID-19, выдвигают на первый план задачу по переосмыслению распределения офисных площадей и трансформации рабочих зон.

Велика вероятность того, что работодателям при адаптации к новым формам организации работы, а именно комбинированию работы из дома и в офисе, придется ускорить переход от традиционного режима офисной работы, где служащему предоставлялось его личное рабочее место, к режиму, когда рабочее место предоставляется ему в дни посещения офиса временно по его запросу. 


\section{Рост объемов удаленной работы в период пандемии COVID-19: последствия и перспективы}

Таким образом, после снятия мер изоляции компании могут чаще прибегать к практикам гибкой организации офисного пространства, когда у работника отсутствует собственное, закрепленное за ним одним рабочее место.

Важно отметить, что большинство опрошенных сотрудников осознают, что, получая больше свободы при выборе индивидуального режима работы и возможности работать из дома, им придется расстаться с индивидуальным рабочим местом. 67\% работников при сочетании офисной и удаленной работы готовы работать в гибком офисном пространстве, рассчитывая одновременно на более широкое разнообразие функционала офисных помещений. Эта готовность сильнее выражена среди менеджеров (77\%) и молодых специалистов (75\%) [Reimagining ..., 2020, p. 19].

Будущий успех компаний сегодня во многом определяется способностью постоянно адаптироваться к изменяющимся условиям функционирования бизнеса, в том числе обусловленным пандемией COVID-19. Введение мер, препятствующих распространению нового коронавируса, значительно ускорило распространение режима удаленной работы и изменения в организации рабочего места. Уже сейчас, по оценкам специалистов международных консалтинговых компаний, распространение новых трудовых практик достигло уровня, который прогнозировался лишь к 2025 г. [Reimagine, 2021, p. 2].

Содержание рабочих процессов, приоритеты рабочей силы и организация рабочего места меняются. По мере этого трансформируется режим работы, приобретающий гибридный характер. Происходит комбинирование работы из дома и в офисе, а предприятия, ориентируясь на предпочтения рабочей силы, начинают переосмысливать организацию трудовых практик и формировать модели рабочего места, позволяющие повысить производительность, а также работать из разнообразных локаций. Это позволяет сохранять и привлекать талантливых сотрудников, но также обостряет проблему поддержания и развития культуры организации, для решения которой необходимо осмыслить новые модели и нормы поведения на рабочем месте.

Очевидно, что основные задачи при переходе на гибридную модель работы (из дома и в офисе) заключаются в минимизации негативного влияния удаленной работы на эффективность сотруд- 
ничества с коллегами, на мотивированность сотрудников следовать организационной культуре компании и на уровень стресса, связанного с изоляцией и отсутствием непосредственных контактов с коллегами и деловыми партнерами. Для этого организациям необходимо в первую очередь постараться обеспечить вовлеченность сотрудников в рабочие процессы и поддерживать их чувство удовлетворенности работой.

В процессе решения данных задач руководители компаний должны найти правильный стиль руководства, который бы поддерживал высокий уровень командной работы в условиях гибридного режима организации труда. Во-первых, необходимо определить: сколько рабочих дней в неделю сотрудник будет работать из дома и сколько на рабочем месте в офисе и / или коворкинге, непосредственно контактируя с коллегами. Во-вторых, переход к новому режиму работы требует дополнительного мониторинга и анализа обратной связи от работников для отслеживания проблем, возникающих при адаптации к новым условиям.

Следует отметить, что переход к комбинированной модели работы, сочетающей удаленную работу и работу в офисе или коворкинге потребует от организаций не только дополнительных временных и трудовых затрат для переосмысления рабочих процессов и изменения организационной политики, но и финансовых инвестиций для переоборудования рабочего пространства и для того, чтобы обеспечить работников необходимыми для продуктивного труда в новых условиях инструментами и технологиями. В частности, для повышения эффективности совместной работы сотрудников в виртуальной среде потребуются инвестиции в разработку и совершенствование виртуальных процессов и обучение работников новым технологическим решениям для эффективного сотрудничества.

\section{Список литературы}

Ляшок В.Ю. Российский рынок труда : время адаптации // Мониторинг экономической ситуации в России: тенденции и вызовы социально-экономического развития. - 2021. - № 1. - С. 23-26.

Dingel J.I., Neiman B. How many jobs can be done at home? - Cambridge (MA) : NBER, 2020. - 14 p. - (NBER working paper series; N 26948). 
Mueller-Langer F., Gomez-Herrera E. Mobility restrictions and remote work : empirical evidence on demand and supply on a European online labour market // COVID economics. $-2020 .-\mathrm{N}$ 63. - P. 1-34.

Reimagine : the new future of work to shape a better world / JLL. - 2020. URL: https://www.us.jll.com/en/trends-and-insights/research/reimagine-the-new-futu re-of-work-to-shape-a-better-world (accessed: 06.04.2021).

Reimagining human experience : how to embrace the new work-life priorities and expectations of a liquid workforce / JLL. - 2020. - Nov. - URL: https://www.jll.co. $\mathrm{uk} /$ content/dam/jll-com/documents/pdf/research/jll-reimagining-human-experience-112020.pdf (accessed: 06.04.2021).

The business case for remote work : for employers, employees, the environment and society / Global workplace analytics. - 2021. - URL: https://globalworkplaceanaly tics.com/whitepapers (accessed: 06.04.2021).

The costs and benefits of working from home / PwC. - 2020. - URL: https://www.pwc.nl/nl/actueel-publicaties/assets/pdfs/pwc-working-from-home-part-II. pdf (accessed: 06.04.2021). 